\title{
ANGIOSARCOMA OF THE THYROID GLAND: A CASE REPORT
}

ENTELA PUCA'; KADIR BURAK KOZA²; UGUR GOZALAN²; EMA LUMI4;SELIM EREKUL³

1 - American Hospital II, Department of Endocrinology

2 - American Hospital II, Department of General Surgery

4 - American Hospital II, Department of Anatomo-Pathology
3 - Regional Hospital of Korca, Department of Endocrinology

Angiosarcoma of the thyroid is a rare and aggressive primary malignant tumor of the thyroid: It rarely occurs in that organ and most of these occur mainly in patients from the mountainous Alpine regions.

We report a case of 68 years old female who presented at our hospital with a rapidly enlarging neck mass associated with compressive symptoms. On clinical examination, the thyroid gland appeared firm during the acts of deglutition. The results of thyroid function tests were for subclinical hyperthyroidism. Ultrasound examination and CT scan showed multinodular goitre with a suspicious nodule from the right thyroid lobe. Fine needle aspiration cytology of the thyroid was suggestive of anaplastic thyroid carcinoma.

A total thyroidectomy was performed. Grossly, the right lobe and left lobe measured $8 \times 7 \times 4 \mathrm{~cm}$, and $8 \times 8 \times 7 \mathrm{~cm}$. Macroscopically the cut surface showed a bulging solid hemorrhagic dark red mass, measuring $4.8 \times 3.2 \times 2.5 \mathrm{~cm}$, at the lower pole of the right lobe. The immunohistochemistry showed CD31 and CD34 positivity and thyroglobulin, calcitonin, and TTF-1 negativity indicating an angiosarcoma. The patients died within 2 months following up from pulmonary hemorrhage.

\section{CONCLUSION}

This case illustrates that Thyroid angiosarcoma is a distinct entity and should be considered and included as a differential diagnosis of poorly differentiated thyroid neoplasm's also outside the mountainous Alpine regions. 